\title{
Panorama do lixo na baixada santista e sua utilização na geração de energia renovável
}

\author{
Overview of waste in lowland santista and its use in renewable energy generation \\ Panorama general de residuos en baixada santista y su uso en generación de energías renovables
}

Recebido: 25/07/2021 | Revisado: 01/08/2021 | Aceito: 27/09/2021 | Publicado: 29/09/2021

\author{
Margareth da Costa Ridelensky \\ ORCID: https://orcid.org/0000-0002-0721-5712 \\ Universidade Santa Cecília, Brasil \\ E-mail: m.ridelensky@gmail.com \\ Aldo Ramos Santos \\ ORCID: https://orcid.org/0000-0003-0236-1910 \\ Universidade Santa Cecília, Brasil \\ E-mail: rsantos@unisanta.br
}

\begin{abstract}
Resumo
Este estudo objetiva apresentar o panorama da situação do lixo na baixada santista, como sua geração, tratamento e destino, assim como apresentar como seu aproveitamento pode ser benéfico na geração de energia não renovável, não só para a questão da energia como principalmente solução para o destino do lixo urbano gerado. Pesquisa exploratória descritiva. Diante das problemáticas existentes com o lixo na RMBS sugere-se algumas alternativas de utilização do lixo como energia renovável, como a retomada do Projeto ELBAS e o exemplo do Aterro DELTA, além da instalação de empresas que concentrem o lixo orgânico produzido pelos municípios de forma centralizada, não só reduz as áreas de deposição, como transformaria o custo da destinação em remuneração para comunidades necessitadas dessas regiões. Apesar da gestão de resíduos urbanos desses municípios atenderem ao disposto na legislação, seus custos e riscos ambientais envolvidos até o seu destino adequado, não só oneram suas economias como levantam críticas sobre os riscos ambientais envolvidos. A retomada de projetos para a coleta do biogás em conjunto com a implantação de ações que valorem o lixo, gera redução de impactos socioambientais e financeiros para as cidades da Região Metropolitana da Baixada Santista.
\end{abstract}

Palavras-chave: Lixo; Energia renovável; Biogás; RMBS.

\begin{abstract}
This studs aims to present an overview of the situation of garbage in the Santos region, as well as its generation, treatment and destination, as well as to present how its use can be beneficial in the generation of non-renewable energy, not only for the energy issue but mainly as a solution for the destination of the generated urban waste. Exploratory descriptive research. In view of the existing problems with garbage in the RMBS, some alternatives for the use of garbage as renewable energy are suggested, such as the resumption of the ELBAS Project and the example of the DELTA Landfill, in addition to the installation of companies that concentrate the organic waste produced by municipalities in a centralized manner, not only reduces the areas of deposition, but also transforms the cost of destination into remuneration for needy communities in these regions. Despite the management of urban waste in these municipalities complying with the legislation, their costs and environmental risks involved until their proper destination, not only burden their economies but raise criticisms about the environmental risks involved. The resumption of projects for the collection of biogas, together with the implementation of actions that value waste, generate a reduction in socioenvironmental and financial impacts for the cities of the Lowland Santista Metropolitan Region.
\end{abstract}

Keywords: Trash; Renewable energy; Biogas; RMBS.

\section{Resumen}

Este estudio tiene como objetivo presentar un panorama de la situación de la basura una la región de Santos, así como su generación, tratamiento y destino, así como presentar cómo su uso puede ser beneficioso una la generación de energía no renovable, no solo para el tema energético pero principalmente como solución para el destino de los residuos urbanos generados. Investigación descriptiva exploratoria. Ante los problemas existentes una la basura una el RMBS, se sugieren algunas alternativas para el uso de la basura como energía renovable, como la reanudación del Proyecto ELBAS y el ejemplo del Relleno Sanitario DELTA, además de la instalación. De las empresas que concentran los residuos orgánicos producidos por los municipios de manera centralizada, no solo reduce las áreas de deposición, sino que también transforma el costo de destino una remuneración para las comunidades necesitadas de estas regiones. A pesar de la gestión de los residuos urbanos una estos municipios cumpliendo una la legislación, sus costos y riesgos ambientales que conllevan hasta su destino adecuado, no solo gravan sus economías sino que generan críticas sobre los riesgos ambientales que conllevan. La reanudación de proyectos de captación de biogás, junto una la implementación de acciones de valorización de residuos, generan una reducción de los impactos socioambientales y económicos para las ciudades de la Región Metropolitana de Baixada Santista. 
Palabras clave: Basura; Energías renovables; Biogás; RMBS.

\section{Introdução}

\subsection{0 lixo}

Este artigo trata do panorama de geração de lixo urbano na baixada santista e a sua utilização como geração de energia renovável através do levantamento de referências bibliográficas.

Pela definição lixo são resíduos provenientes de atividades domésticas, industriais, comerciais, entre outros, que não prestam e são jogados fora. (Michaellis, 2021). Para a Política Nacional de Resíduos Sólidos, Lei no 12.305/2010 define rejeito como resíduos sólidos que, depois de esgotadas todas as possibilidades de tratamento e recuperação por processos tecnológicos disponíveis e economicamente viáveis, não apresentem outra possibilidade que não a disposição final ambientalmente adequada (Brasil, 2010).

Pode-se inferir que diante dessas duas definições lixo e rejeitos são sinônimos e este artigo tratará esse tema dessa forma, demonstrando que se adequadamente gerido, o resíduo urbano não se enquadra com lixo, pois todas as suas origens possuem algum tipo de destino, diferente de disposição.

No Brasil a gestão dos resíduos sólidos já era realizada antes da publicação de políticas que a regularizaram, mas era de forma descentralizada e de acordo com as exigências locais ambientais.

Em 2010 foi publicada a Política Nacional dos Resíduos Sólidos em 2010 (Brasil,2010). No Estado de São Paulo, esse regramento ocorreu quatro anos antes com publicação da Política de Resíduos Sólidos instituída pela Lei nº 12.300/2006 (São Paulo, 2006), no entanto somente regulamentada um ano antes da publicação da Política Nacional através do Decreto 54.645/2009 (São Paulo, 2009).

Dentre outras exigências, ambas as políticas definem a obrigatoriedade de Planos aos Estados e Municípios que contemplem metas para redução, reutilização, reciclagem, entre outras, com vistas a reduzir a quantidade de resíduos e rejeitos encaminhados para disposição final ambientalmente adequada e metas para o aproveitamento energético dos gases gerados nas unidades de disposição final de resíduos sólidos (Brasil, 2010; São Paulo, 2009)

Conforme Instituto e Pesquisas Tecnológicas (2018) o Plano Regional da Gestão Integrada de Resíduos Sólidos da Baixada Santista (PRGIRS/BS) apresenta o IGR - Índice de Gerenciamento de Resíduos pela Região Metropolitana da Baixada Santista, o qual foi desenvolvido pela Secretaria do Estado de Meio Ambiente e tem por finalidade avaliar a gestão dos resíduos nos municípios paulistas, com vistas a fornecer subsídios para a proposição e implementação de políticas públicas estaduais, explorando temas, como:

- instrumentos para a política de resíduos sólidos,

- programas ou ações municipais,

- coleta e triagem e tratamento e disposição.

O Quadro 1 elaborado pelo Instituto de Pesquisas Tecnológicas, apresenta o Índice de Geração de Resíduos - IGR calculado com dados do ano de 2012 e 2014 para os municípios da Região Metropolitana da Baixada Santista - RMB. 
Quadro 1: IGR da RMB referente aos anos de 2012 e 2014.

\begin{tabular}{|c|c|c|c|c|}
\hline \multirow{2}{*}{ Município } & \multicolumn{2}{|c|}{$\mathbf{2 0 1 2}$} & \multicolumn{2}{|c|}{ 2014 } \\
\cline { 2 - 5 } & IGR & Categoria & IGR & Categoria \\
\hline Bertioga & 7,4 & Mediana & 0,4 & Mediana \\
\hline Cubatão & 5,1 & Ineficiente & 0,0 & Não Informado \\
\hline Guarujá & 8,6 & Eficiente & 7,4 & Mediana \\
\hline Itanhaém & 6,3 & Mediana & 7,3 & Mediana \\
\hline Mongaguá & 6,4 & Mediana & 0,0 & Não Informado \\
\hline Peruíbe & 0,0 & Não Informado & 7,3 & Mediana \\
\hline Praia Grande & 8,6 & Eficiente & 8,1 & Eficiente \\
\hline Santos & 8,8 & Eficiente & 0,0 & Não Informado \\
\hline São Vicente & 8,1 & Eficiente &
\end{tabular}

Fonte: Instituto de Pesquisas Tecnológicas (2018).

A partir destas informações o Instituto de Pesquisas Tecnológicas (2018) traçou dentre outros, alguns na gestão de resíduos sólidos na RMBS são:

- Aumento da geração de resíduos na alta temporada;

- Método de coleta com amontoamento dos sacos de resíduos nas esquinas, a fim de otimizar o trabalho da equipe de coleta, atraindo animais vetores de doenças;

- Desequilíbrio em relação às finanças da gestão de RSU;

- Falta de legislação específica para os resíduos de limpeza urbana;

- Ausência de plano de gerenciamento dos resíduos de poda de árvore (resíduos volumosos e com alto poder energético)

e dos resíduos de varrição de feira livre (grandes geradores de resíduos orgânicos);

- Alto custo de manejo e disposição final dos resíduos;

- Grandes distâncias entre geradores, transbordos e destinações finais, ocasionando um grande custo;

No mesmo ano, através da divulgação do Inventário Anual de Gestão de Resíduos Sólidos - IGRS a Companhia de Saneamento Ambiental do Estadual de São Paulo (2018) estabelece um comparativo entre os Índices de Geração de resíduos IGR e o Índice da Qualidade de Resíduos - IQR referente aos municípios da RMBS, conforme é apresentado pela Tabela 1, demonstrando que no geral $100 \%$ das cidades não possuem Termos de Ajuste de Conduta e apesar de alguns municípios destinarem seus resíduos para aterros em outros municípios, todos os destinos escolhidos estão adequadamente licenciados. 
Tabela 1: IGR e IQR segundo o IGRS da CETESB (2018).

\begin{tabular}{|c|c|c|c|}
\hline Município & IGR (ton/dia) & IQR (2018) & $\begin{array}{c}\text { Licenciamento } \\
\mathrm{LI} / \mathrm{LO}^{1}\end{array}$ \\
\hline Peruíbe & 53,43 & 9 (Condição Adequada) & $\begin{array}{c}\text { TAC - Não } \\
\text { LI e LO - SIM }\end{array}$ \\
\hline Itanhaém & 79,64 & 9 (destino Mauá) & $\begin{array}{c}\text { TAC - Não } \\
\text { LI e LO - SIM }\end{array}$ \\
\hline Mongaguá & 44,39 & $\begin{array}{c}9 \text { (destino Aterro } \\
\text { Particular - Santos) }\end{array}$ & $\begin{array}{c}\text { TAC - Não } \\
\text { LI e LO - SIM }\end{array}$ \\
\hline Praia Grande & 284,23 & $\begin{array}{l}9 \text { (destino Aterro } \\
\text { Particular) }\end{array}$ & $\begin{array}{c}\text { TAC - Não } \\
\text { LI e LO - SIM }\end{array}$ \\
\hline Guarujá & 286,24 & $\begin{array}{c}9 \text { (destino Aterro } \\
\text { Particular) }\end{array}$ & $\begin{array}{c}\text { TAC - Não } \\
\text { LI e LO - SIM }\end{array}$ \\
\hline Santos & 389,37 & $\begin{array}{l}9 \text { (destino Aterro } \\
\text { Particular) }\end{array}$ & $\begin{array}{c}\text { TAC - Não } \\
\text { LI e LO - SIM }\end{array}$ \\
\hline Bertioga & 48,58 & $\begin{array}{c}9 \text { (destino Aterro } \\
\text { Particular - Santos) }\end{array}$ & $\begin{array}{c}\text { TAC - Não } \\
\text { LI e LO - SIM }\end{array}$ \\
\hline Cubatão & 116,78 & $\begin{array}{c}9 \text { (destino Aterro } \\
\text { Particular - Santos) }\end{array}$ & $\begin{array}{c}\text { TAC - Não } \\
\text { LI e LO - SIM }\end{array}$ \\
\hline São Vicente & 326,24 & $\begin{array}{l}9 \text { (destino Aterro } \\
\text { Particular) }\end{array}$ & $\begin{array}{c}\text { TAC - Não } \\
\text { LI e LO - SIM }\end{array}$ \\
\hline
\end{tabular}

${ }^{1}$ LI - Licença de Instalação; LO - Licença de Operação.

Fonte: Adaptado pelo Autor de CETESB (2018)

Para o lixo orgânico, com potencial na geração de metano, o incentivo a ações de captura e produção do biogás na manutenção da energia utilizada pelo processo de reciclagem das cooperativas de catadores, reduziria os custos de transporte e destino gastos pelos municípios, assim como a redução de riscos ambientais e valoração e aumento da renda da camada social mais necessitada nesses municípios da Região Metropolitana da Baixada Santista.

O lixo se bem gerido, transforma-se num grande instrumento de geração de empregos e inclusão social, diminuindo os custos e gerando receita para o município.

\subsection{Energia renovável}

Energia renovável é uma energia derivada de processos naturais que são ou podem ser constantemente reabastecidos e incluem energia solar, eólica, biomassa, geotérmica, hidrelétrica, energia maremotriz e biocombustíveis (Barbosa, 2014, apud Scholten \& Bosman, 2013, p. 12; IEA, 2004, p. 12). É a energia que mantém um ciclo equilibrado de produção e consumo, porque é gasta em quantidade e velocidade nas quais a natureza pode repô-la (Barbosa, 2014).

Pedroso et al (2018) citando os dados da Agência Internacional de energia - IEA, detalha que a demanda global total de energia estimada será de 17.934 milhões de toneladas equivalentes de petróleo (Mtep) e a demanda por fontes renováveis na matriz energética mundial crescerá 4\% entre 2014 e 2040.

Ao contrário do que se observa na matriz mundial, cujo aumento poderá atingir quase $9 \%$ em 2040, a demanda de energia primária no Brasil atingiu 305,2 Mtep em 2014, sendo 185,1 Mtep (61\%) em energia oriunda de fontes não renováveis e 120,1 Mtep (39\%) de fontes renováveis (Pedroso et al, 2018).

O Quadro 2 detalha a matriz energética do Brasil atualmente. 
Quadro 2: Composição da Matriz energética no Brasil.

\begin{tabular}{|c|c|c|}
\hline Fonte de Energia & Tipo de Energia & $\begin{array}{c}\text { Participação da Produção de } \\
\text { Energia }\end{array}$ \\
\hline Petróleo e derivados & \multirow[t]{4}{*}{ Não Renovável } & $64,9 \%$ \\
\hline Gás Natural & & $22,4 \%$ \\
\hline Carvão Mineral & & $9,5 \%$ \\
\hline Energia Nuclear e outras Fontes & & $3,2 \%$ \\
\hline $\begin{array}{l}\text { Biomassa: biocombustíveis (etanol, bioetanol, biodiesel } \\
\text { e H-BIO); combustíveis sólidos (lenha, carvão, resíduos } \\
\text { da agroindústria, bagaço de cana), biomassa e biogás. }\end{array}$ & \multirow[t]{3}{*}{ Renovável } & $60,6 \%$ \\
\hline Energia Hidrelétrica & & $29,2 \%$ \\
\hline Outras Fontes: Energia Solar e Eólica & & $10,2 \%$ \\
\hline
\end{tabular}

Fonte: Adaptado pelo autor de Pedroso et al (2018).

A matriz energética nacional é diversificada e conta com importante uso de fontes renováveis. (Oliveira et al, 2018). No Brasil, a biomassa total, que inclui biocombustíveis líquidos, gasosos ou sólidos, usados na produção de energia automotiva, na forma de vapor ou eletricidade é superior à energia das usinas hidrelétricas, todavia se não houver um forte investimento no setor, sua contribuição futura continuará estática nas próximas décadas (Pedroso et al, 2018 apud Walter e Nogueira, 2016). Entre 2004 e 2015, foram implantadas nos aterros de resíduos do País somente 9 usinas termelétricas, que juntas geram 86,3 MW de energia elétrica, e duas usinas que produzem biometano. Considerando as estimativas existentes, o Brasil explora somente de 7 a 20\% do biogás produzido nos aterros de resíduos para fins energéticos (Nascimento et al, 2019).

Crovador et al (2018) em seu estudo sobre as estimativas de produção de biogás em aterros conclui que conhecer a provável curva de geração de biogás pelos resíduos sólidos confinados é um fator primordial ao estudo da viabilidade técnica e econômica da venda da energia do biogás, pois norteia o cálculo da provável receita a ser obtida com a recuperação energética das emissões gasosas, bem como o custo do sistema necessário para a coleta e aproveitamento, que depende diretamente da quantidade e características do biogás gerado. Marques (2019) em um estudo sobre o Aterro no município de Palmas, Tocantins acredita que este aterro em específico com a geração de biogás pode abastecer cerca de 3.251 residências se transformado em energia elétrica.

Boff e Boff (2017) conclui que na busca da implantação de projetos que objetivem a energia renovável é necessária a atenção a Inovação Tecnológica e as Políticas Públicas.

\subsection{Baixada santista}

De acordo com Cunha e Oliveira (2015) a primeira região metropolitana brasileira sem a presença de uma capital estadual, está localizada no Estado de São Paulo e é denominada Baixada Santista. Criada pela Lei Complementar Estadual no 815 de 30 de junho de 1996, sendo composta por nove municípios: Peruíbe, Itanhaém, Mongaguá, Praia Grande, Guarujá, Santos, Bertioga, Cubatão e São Vicente, totalizando $2.445 \mathrm{~km}^{2}$.

A Região Metropolitana (RM) da Baixada Santista está situada na área central do litoral do estado de São Paulo, a partir do resultado de um processo de urbanização iniciado a partir da migração intra e extrarregional após a Segunda Guerra Mundial, como consequência da industrialização do Sudeste brasileiro, na esteira da política de substituição de importações promovida pelos governos federais e iniciada décadas antes. (Carriço e Saleme, 2018)

A Região Metropolitana da Baixada Santista, criada em 1996, tem seus limites idênticos aos das Regiões Administrativa e de Governo de Santos (Assembleia Legislativa de São Paulo, 2008) 
Figura 1: Mapa da Região Metropolitana da Baixada Santista.

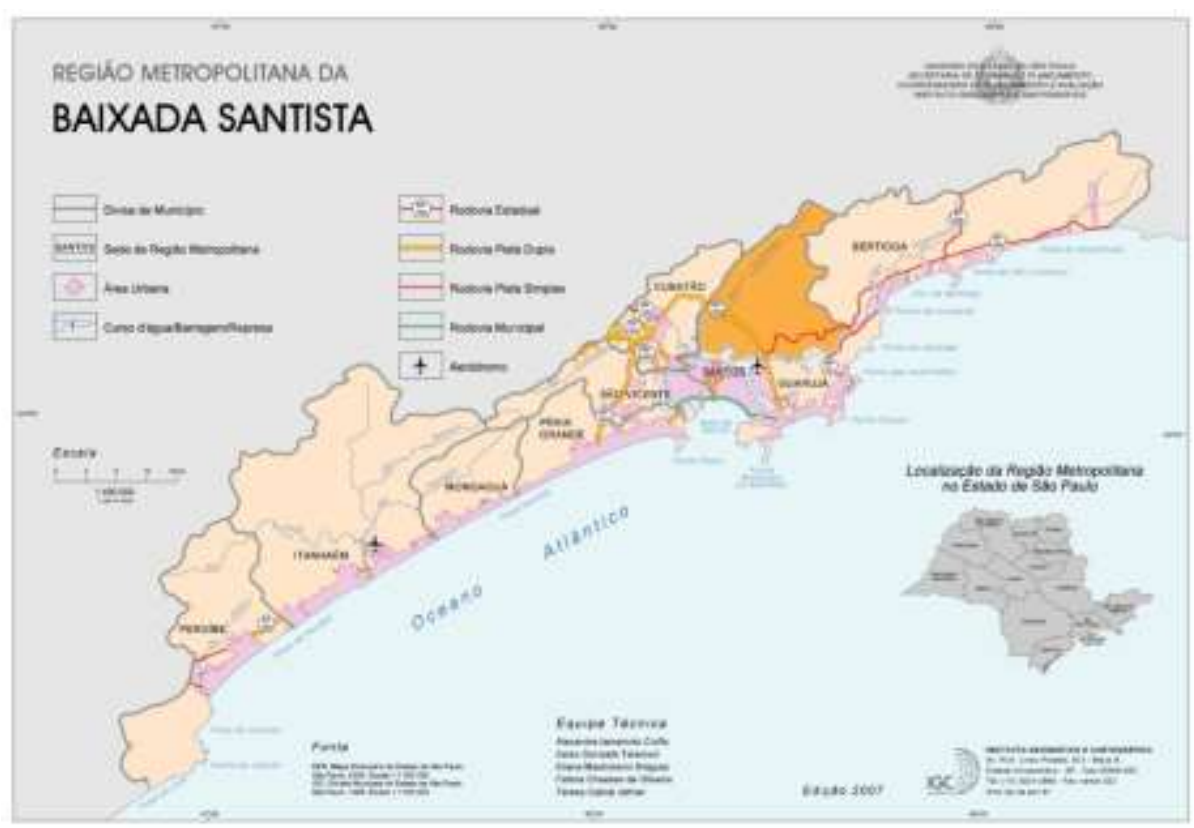

Fonte: http://www.igc.sp.gov.br/produtos/mapas_rad41d.html?

De acordo com Cunha e Oliveira (2015) no início da segunda década do século 21, a população total da Região Metropolitana da Baixada Santista, pelo Censo realizado pelo IBGE em 2011 era estimada 1.691.441 habitantes. A Tabela 2 apresenta a estratigrafia dessa população por município da RMBS.

Tabela 2: População Região Metropolitana da Baixada Santista de acordo com o PIB $^{2}$ e IDH ID $^{3}$.

\begin{tabular}{lcccc} 
& Area $\left(\mathrm{Km}^{2}\right)$ & População & PIB $(\mathrm{R} \$) 2008$ & IDH \\
\hline Bertioga & 491,701 & 50.304 & 665.977 .000 & 0,792 \\
Cubatão & 142,281 & 120.293 & 5.786 .553 .000 & 0,772 \\
Guarujá & 142,589 & 294.669 & 3.429 .098 .000 & 0,788 \\
Itanhaém & 599,017 & 89.232 & 824.091 .000 & 0,779 \\
Mongaguá & 143,171 & 47.100 & 447.405 .000 & 0,783 \\
Peruíbe & 326,214 & 61.030 & 614.539 .000 & 0.783 \\
Praia Grande & 149,079 & 272.390 & 2.780 .735 .000 & 0,796 \\
Santos & 280,300 & 419.614 & 22.546 .134 .000 & 0,871 \\
São Vicente & 148,424 & 336.809 & 2.898 .356 .000 & 0,798 \\
\hline
\end{tabular}

2PIB - Produto Interno Bruto; 3'́ndice de Desenvolvimento Humano.

Fonte: Cunha e Oliveira, 2015 apud Fundação SEADE - Censo IBGE (2011).

A Região Metropolitana abriga importantes polos turísticos e empresariais do país, como:

- a primeira cidade fundada do Brasil - São Vicente,

- o maior Porto da América Latina - Porto de Santos, considerado o mais importante do país e o centro do PIB brasileiro, distribuído por três municípios Santos, Guarujá e Cubatão;

- região de importante polo turístico litorâneo, localizado aos pés do Parque Estadual da Serra do Mar e de outros ecossistemas sensíveis, como os remanescentes de mangues e restinga.

- base do pré-sal da Bacia de Santos 


\section{- Refinaria Presidente Bernardes e Terminal Aquaviário Alemoa.}

- Importante Polo Industrial de Cubatão.

A Baixada Santista possui uma estrutura industrial dinâmica, cujos segmentos mais expressivos são o refino de petróleo e a metalurgia básica, além do ramo químico. A importância desses setores é complementada por inúmeras plantas industriais de bens intermediários. As indústrias de fabricação de alimentos e bebidas também são atividades importantes.

De acordo com o exposto este artigo objetiva apresentar o panorama da situação do lixo na baixada santista, como sua geração, tratamento e destino, assim como apresentar como seu aproveitamento pode ser benéfico na geração de energia não renovável, não só para a questão da energia como principalmente solução para o destino do lixo urbano gerado.

\section{Metodologia}

Através de metodologia de pesquisa de natureza qualitativa (Flick, 2009) e exploratória descritiva (Gil, 2008), o artigo procura demonstrar através de estudos publicados em revistas conceituadas a importância da coleta do gás de aterros sanitários e a sua transformação em energia renovável.

Foram pesquisados em bancos de dados de revistas conceituadas, assim como estudos publicados por órgãos competentes no assunto de forma a este autor traçar um panorama para responder à pergunta norteadora: "Os lixos dispostos em aterros geram energia renovável no Brasil? “

A pesquisa para seleção dos artigos considerou descritores como: utilização do gás de aterros controlados, biogás em aterros controlados. Sendo selecionados aqueles que apresentavam textos na integram em português e a sua publicação atendendo ao espaço temporal entre 2015 e 2021.

\section{Resultados e Discussão}

Diante das problemáticas existentes com o lixo na RMBS sugere-se algumas alternativas de utilização do lixo como energia renovável.

O Brasil detém uma das matrizes energéticas mais sustentáveis do mundo. Neste sentido, 47,3\% da oferta interna de energia são provenientes de fontes renováveis, enquanto que a média mundial é de 12,9\%. (Gehm, 2016)

A geração de energia por meio do biogás oriundo da decomposição dos resíduos sólidos em aterros sanitários se apresenta como uma alternativa ambientalmente e economicamente viável para a solução de um dos mais graves problemas enfrentados pela sociedade: o acúmulo de lixo. (Martins, Silva \& Carneiro, 2017)

Sabe-se que o gás metano é uma importante fonte de energia, mas também que este é um gás de efeito estufa com potencial de aquecimento cerca de 20 vezes maior que o dióxido de carbono e responsável por $25 \%$ do aquecimento global. Desta forma, pode-se afirmar que a redução do gás metano liberado no meio ambiente, através de sua coleta e posterior utilização traz inúmeras vantagens, ao meio ambiente e também pode permitir uma gestão mais adequada de resíduos sólidos no país. (Gehm, 2016 apud Usepa, 2007)

A produção de energia através do biogás do lixo em aterros sanitários representa ganhos para a sociedade, pois além da possibilidade de gerar empregos, reduzir subempregos e aumentar a arrecadação de impostos, gera melhorias ao meio ambiente com a contenção de emissões de $\mathrm{CO}_{2}$ e, redução do uso de combustíveis fósseis. (Martins, Silva \& Carneiro, 2017)

Um dos estudos de caso mais famosos e discutidos do Brasil é o aterro sanitário de Gramacho. Abreu, Avelino \& Monaco (2011) estudaram os benefícios socioambientais da implantação de uma termoelétrica a partir do biogás do lixo, listando diversas contribuições para o País dentre as quais, serão listadas as principais, conforme segue:

- contribuição para a sustentabilidade ambiental local; 
- contribuição para o desenvolvimento das condições de trabalho e a geração líquida de empregos; contribuição para a distribuição de renda;

- contribuição para capacitação e desenvolvimento tecnológico (possibilidade de reprodução da tecnologia empregada, observando o seu efeito demonstrativo, avaliando, ainda, a origem dos equipamentos, a existência de royalties e de licenças tecnológicas e a necessidade de assistência técnica internacional);

- contribuição para o desenvolvimento regional, que pode ser medida a partir da integração do projeto com outras atividades socioeconômicas na região de sua implantação.

- conscientização da população com relação ao desenvolvimento de práticas sustentável e produção de energia renovável e limpa

São poucos os projetos que foram implantados, mas um exemplo na Baixada santista é o Projeto ELBAS. De acordo com ENSINAS (2003) apud COSIPA (1980) o projeto ELBAS visava o aproveitamento do biogás de um aterro sanitário na Baixada Santista que depois de devidamente tratado seria transportado por tubulação à COSIPA (Companhia Siderúrgica Paulista) atual USIMINAS, sendo usado como complemento aos derivados petróleo consumidos na empresa e melhoraria a ordenação da coleta e destinação final do lixo na região, diminuindo o lançamento de resíduos sólidos a céu aberto e muitas vezes em áreas ribeirinhas ou de manguezais.

O mesmo autor, desenvolve uma proposta no aterro Delta, no município de Campinas, sugerindo que com a captura adequada do biogás tem a capacidade de geração de energia elétrica de 3 MW em 2003 para 4 MW em 2006, utilizando como geração a captação do biogás. No entanto pontua que alguns problemas teriam que ser sanados para o aumento dessa eficiência de captação do gás no aterro como: melhora na eficiência da medição das outras vias de emissão de metano, como a superfície do aterro e a drenagem de chorume, concentração na deposição do lixo, evitando a perda do gás quando a deposição é realizada de forma aleatória em diversas partes do aterro, melhorias nas etapas do projeto do aterro, aumentando o aproveitamento do gás Uma alternativa também possível para acelerar o uso do biogás é a instalação de drenos horizontais que atendam cada camada de lixo após a sua cobertura com terra. (ENSINAS, 2003)

A instalação de empresas que concentrem o lixo orgânico produzido pelos municípios de forma centralizada, não só reduz as áreas de deposição, como transformaria o custo da destinação em remuneração para comunidades necessitadas dessas regiões.

\section{Considerações Finais}

Atualmente o maior problema dos municípios brasileiros é a destinação adequada de seus rejeitos urbanos, não sendo diferente para os municípios da Região Metropolitana da Baixada Santista.

De acordo com este artigo observa-se que apesar da gestão de resíduos urbanos desses municípios atenderem ao disposto na legislação, seus custos e riscos ambientais envolvidos até o seu destino adequado, não só oneram suas economias como levantam críticas sobre os riscos ambientais envolvidos nessa gestão, já que alguns municípios percorrem diversos quilômetros diariamente até o destino adequado em municípios vizinhos, atravessando Áreas de Preservação Ambiental como a Serra do Mar até chegarem a seu destino final.

A retomada de projetos com objetivos como o ELBAS, seria importante não só para economia financeira e ambiental dos municípios da região, como reduziria os impactos ambientais inerentes ao processo de transporte e destino, assim como prevaleceria a indução de projetos às comunidades em situações críticas da região como as ribeirinhas.

Propõem-se ainda, em conjunto estudos que verifiquem a viabilidade da valoração do lixo, relacionando com o envolvimento da camada social que já vive a partir de sua geração e descarte; veiculação de campanhas conjuntas à população quanto à importância da segregação do lixo, redução dos volumes dos resíduos orgânicos e aumentando dos volumes dos 
recicláveis - reduzindo o total de geração de resíduos urbanos destinado a aterros e aumentando a reciclagem; benefícios fiscais a implantação de empresas de natureza de tratamento de resíduos na região que ofereçam alternativas ambientalmente adequadas a esse lixo; ações de intensificação do processo de logística reversa focando no aumento de postos de recebimento de resíduos como embalagens diversas, pilhas, lâmpadas, remédios; e, por fim a determinação de contra partidas em contratos de implantação de grandes empreendimentos com representativo impacto ambiental e social relacionadas à geração do lixo.

Sugere-se que sejam ampliados os estudos e a implantação de novas tecnologias que não só gerem energia a partir do lixo, mas que diversifiquem a matriz energética na região metropolitana da baixada santista, utilizando matrizes potenciais na região como energia das marés, geração de energia eólica offshore e o incentivo a implantação da geração de energia solar, incorporando essas exigências em novos projetos implantados na região, tanto públicos como privados.

\section{Referências}

Abreu, F. V., Avelino, M. R., \& Monaco, D. P. (2011). Estudo Técnico, Econômico e Ambiental da geração de energia através do biogás de lixo - o caso do aterro sanitário de Gramacho. Cadernos unifoa, 6 (2). http://revistas.unifoa.edu.br/index.php/cadernos/article/view/1056/922.

Barbosa, G. G. (2014). Recursos Naturais Renováveis e Produção de Energia. Revista Política Hoje, 23(1), 193-215. https://periodicos.ufpe.br/revistas/politicahoje/article/view/3760/3064.

Brasil (2010). Lei Federal nº 12.305 de agosto de 2010. Institui a Política Nacional de Resíduos Sólidos; altera a Lei n 9.605 , de 12 de fevereiro de 1998; e dá outras providências, Brasília, DF: Presidência da República. http://www.planalto.gov.br/ccivil_03/_ato2007-2010/2010/lei/112305.htm.

Boff, S. O. \& Boff, V. A. (2017). Inovação tecnológica em energias renováveis no Brasil como imperativo da solidariedade intergeracional. Revista de Direito Econômico e Socioambiental, 8(2), 282-302. https://dialnet.unirioja.es/servlet/articulo?codigo=6172798.

Carriço, J. M., \& Saleme, E. R. (2018). Dos planos municipais ao plano de desenvolvimento urbano integrado: a aprovação do plano de desenvolvimento urbano integrado pela região metropolitana da baixada santista. Brasil Metropolitano em Foco: desafios à implementação do Estatuto da Metrópole. http://repositorio.ipea.gov.br/handle/11058/8686.

CETESB - Companhia Ambiental do Estado de São Paulo. (2018). Inventário Estadual de Resíduos Urbanos. https://cetesb.sp.gov.br/residuossolidos/wpcontent/uploads/sites/26/2019/06/Invent\%C3\%A1rio-Estadual-de-Res\%C3\%ADduos-S\%C3\%B3lidos-Urbanos-2018.pdf.

Crovador, M. I. C., Schirmer, W. N., Martins, K. G., Franqueto, R., \& Jucá, J. F. T. (2018). Estimativa da produção de biogás em aterro sanitário subtropical brasileiro. Revista em Agronegócio e Meio Ambiente, 11(1). http://dx.doi.org/10.17765/2176-9168.2018v11n1p227-251.

Cunha, C. M. L., \& Oliveira, R. C. (2015) Baixada Santista - Uma contribuição à análise socioambiental. Editora UNESP. https://cetesb.sp.gov.br/escolasuperior/wp-content/uploads/sites/30/2016/06/Vinicius-Travalini_Cap3-Livro_Baixada-Santista_Umacontribui\%C3\%A7\%C3\%A3o-\%C3\%A0-an\%C3\%A1lise-geoambiental.pdf.

Ensinas, A. V. (2003). Estudo da geração de biogás no aterro sanitário delta em Campinas - SP. Dissertação (Mestrado em Engenharia Mecânica), Universidade Estadual de Campinas, Campinas, SP. http://repositorio.unicamp.br/jspui/handle/REPOSIP/264904.

Flick, U. (2009). Introdução a pesquisa qualitativa. (3a ed.). Artmed. http://www2.fct.unesp.br/docentes/geo/necio_turra/PPGG\%20-\%20PE SQUISA \%20QUALI\%20PAR A\%20GEOGRAFIA/flick\%20-\%20introducao\%20a\%20pesq\%20quali.pdf.

Gehm, S. C. (2016). Estudo da capacidade de geração de energia elétrica a partir do biogás produzido através do lixo doméstico do município de Ijuí - RS, Universidade do Noroeste do Rio Grande do Sul, UNIJUI. http://bibliodigital.unijui.edu.br:8080/xmlui/handle/123456789/4132.

Gil, A. C. (2008). Métodos e técnicas de pesquisa social. (6ª ed.). Atlas. https://ayanrafael.files.wordpress.com/2011/08/gil-a-c-mc3a9todos-etc3a9cnicas-de-pesquisa-social.pdf.

Instituto de pesquisas tecnológicas. (2018). Plano Regional de Gestão Integrada de Resíduos Sólidos da Baixada Santista PRGIRS/BS, Minuta para Audiência Pública. https://www.ipt.br/download.php?filename=1617-PRGIRS_BS.pdf.

Marques, M. S. (2019). Qualidade ambiental e estudo da produção e aproveitamento energético do biogás produzido pelo aterro sanitário de Palmas - TO. Dissertação (Mestrado em Engenharia Ambiental) - Universidade Federal do Tocantins, Palmas, TO. http://hd1.handle.net/11612/1059.

Martins, L. O. S., Silva, L. T., \& Carneiro, R. A. F. (2017). Análise da viabilidade econômica e financeira da implantação de usina de geração de energia a partir de resíduos sólidos urbanos no município de Santo Antônio de Jesus. Revista Livre de Sustentabilidade e Empreendedorismo. 2 (2), 142-166. http://relise.eco.br/index.php/relise/article/view/76/59.

Michaelis, Dicionário Brasileiro da Língua Portuguesa. (2021). Lixo. https://michaelis.uol.com.br/moderno-portugues/busca/portugues-brasileiro/lixo.

Nascimento, M. C. B., Freire, E. P., Dantas, F. de A. S., \& Giansante, M. B. (2019) Estado da arte dos aterros de resíduos sólidos urbanos que aproveitam o biogás para geração de energia elétrica e biometano no Brasil, Revista Engenharia Sanitária Ambiental, 24 (1). https://doi.org/10.1590/S1413-41522019171125.

Oliveira, A. P. M., Fuganholi, N. S., Cunha, P. H. S., Barelli, V. A., Bunel, M. P. M., \& Novazzi, L. F. (2018). Análise Técnica e Econômica de fontes de energia renováveis. The Journal of Engineering and Exact Sciences - JCEC, 04 (1). https://periodicos.ufv.br/jcec/article/view/2502/1053. 
Pedroso, L. L. A. Silva, F. F., Silva, F. F., Melo, Á. M., Junior, M. E., Shimoya, A., Matias, Í. O., \& Souza, C. L. M. (2018). Demandas atuais e futuras da biomassa e da energia renovável no Brasil e no mundo. Brazilian Journal of Development, 04 (5), 1980-1996. https://www.brazilianjournals.com/index.php/BRJD/article/view/231.

São Paulo. Lei $\mathrm{n}^{\circ}$ 12.300/2006. Institui a Política Estadual de Resíduos Sólidos e define princípios e diretrizes. Assembleia Legislativa de São Paulo. https://www.al.sp.gov.br/norma/61778.

São Paulo. Decreto 54.645/2009 - Regulamenta dispositivos da Lei n ${ }^{\circ} 12.300$ de 2006, que institui a Política Estadual de Resíduos Sólidos, e altera o inciso I do artigo 74 do Regulamento da Lei $\mathrm{n}^{\circ}$ 997, de 1976, aprovado pelo Decreto $\mathrm{n}^{\circ}$ 8.468, de 1976. Assembleia Legislativa de São Paulo. https://www.al.sp.gov.br/norma/157206.

São Paulo. (2008). Região Metropolitana da Baixada Santista. Assembleia Legislativa de São Paulo. https://www.al.sp.gov.br/noticia/?id=258811. 